\title{
PARTICIPAÇÃO POLÍTICA PEER-TO-PEER? O CASO DA APA FUNK EM RIO DE JANEIRO.
}

\author{
Julia Stadler
}

Mestra (Magister Artium) em Ciências Políticas com especialização em América Latina e em História Contemporânea pela Universidade de Tübingen, Alemanha (2008). É doutoranda de Ciências Políticas no Instituto de Estudos Sociais e Políticos (IESP) da Universidade do Estado do Rio de Janeiro (UERJ).

\begin{abstract}
Resumo
O presente artigo aplica a teoria da produção do commons ao campo da participação política. Trata-se de um estudo de caso da Associação de Profissionais e Amigos do Funk (APAFUNK) no qual se discute a transformação de atores marginalizados em atores políticos dentro do sistema representativo: por que eles optaram, num ambiente de confronto e tensão, pelo caminho do sistema político tradicional? Analisamos a sua lógica de ação e participação política e examinamos a sua geografia social, mapeando as suas atividades pelo prisma da identidade coletiva. Daremos uma introdução ao panorama maior das dificuldades de ser um ator dentro do sistema representativo que não só representa os historicamente despolitizados, mas também uma lógica de participação claramente diferente do mainstream.
\end{abstract}

\section{Palavras-chave}

Produção do comum. Produção peer to peer. Governança peer to peer.

\begin{abstract}
This paper applies the theory of production of commons to political participation field. This is a case study of the Associação de Profissionais e Amigos do Funk (APAFUNK) in which it is discussed the transformation of marginalized actors into political actors within the representative system: why did they choose in an atmosphere of confrontation and tension for the traditional politician system? We analyze the logic of their action and political participation and we examine its social geography, mapping their activities through the prism of collective identity. We give an introduction to the big picture of the difficulties of being an actor inside the representative system that not only historically represents the apolitical ones, but also a logic of participation clearly different from the mainstream.
\end{abstract}

Keywords

Production of the common. Peer to peer production. Peer to Peer Governance.

\section{INTRODUÇÃO}

Em 2007 o secretário de segurança do estado Rio de Janeiro, José Mariano Beltrame, assina a resolução 013 que dá aos policiais o poder de vetar qualquer evento social, esportivo ou cultural no estado do Rio de Janeiro. Essa resolução se encontra na tradição da lei estadual 5.265/2008 que cedia totais poderes à policia de interditar os famosos baile funks na cidade Rio de Janeiro, além de criar regras e condições que dificultaram ou impossibilitaram eventos culturais em áreas sociais precárias. Em favelas ocupadas pela Unidade de Polícia Pacificadora 
(UPP) os bailes sumiram completamente. Paralelamente, pessoas envolvidas com os bailes se juntam para questionar e combater de forma proativa esta política de repressão contra a cultura do funk e em dezembro 2008 é fundada a Associação dos Profissionais e Amigos do Funk (APA Funk). Esta organização de "favelados", socialmente e politicamente marginalizados, consegue que a Assembleia Legislativa do Estado Rio de Janeiro passe a lei "funk é cultura" (Lei 5543/2009), aconteça o primeiro baile numa favela com UPP e em 2012 o presidente da APA Funk, MC Leonardo, se candidate a vereador pelo Partido Socialismo e Liberdade (PSOL) na cidade do Rio de Janeiro. O movimento do funk revelou-se um movimento de direitos humanos. Ao escrever este artigo, em agosto de 2013, o governador do Rio de Janeiro, Sergio Cabral, revoga a resolução 013 que na prática era a ferramenta chave para a proibição de eventos que envolvem um funk mais popular. Porém, ainda há vários relatos de bailes interditados por responsáveis da Polícia Militar.

Neste estudo de caso discuto junto com alguns profissionais e amigos do funk carioca ${ }^{1}$ a APA Funk e a transformação desses atores marginalizados ${ }^{2}$ em atores políticos dentro do sistema representativo. Por que eles optaram num ambiente de confronto e tensão pelo caminho do sistema político tradicional, ou seja, pelo víeis de mudança legislativa e de políticas públicas? Analisamos a sua lógica de ação e participação política e examinamos a sua geografia social, mapeando as suas atividades pelo prisma da identidade coletiva. Daremos uma introdução ao panorama maior das dificuldades de ser um ator dentro do sistema representativo que não só representa os historicamente despolitizados, mas também uma lógica de participação claramente diferente do mainstream.

Dentro das ciências sociais, as teorias tradicionalmente mais indicadas para estudar um grupo como este, seriam teorias de movimentos sociais, cidadania e de participação política. Porém, como veremos, estas teorias não conseguem explicar muito bem nem a lógica interna da APA Funk, nem as ações pelas quais optaram. Em contraponto, as teorias de peer-to-peer production prometem captar estas dinâmicas. Portanto, num primeiro passo irei discutir um catálogo de características de peer-production da P2P Foundation e apresentar enquanto se pode traduzir esta produção entre pares aos estudos de participação política.

Trata-se, de certa forma, de uma pesquisa propriamente peer-to-peer, e não de uma pesquisa cientista social tradicional (e.g. grupo focal ou etnografia): As entrevistas se tornaram

\footnotetext{
${ }^{1}$ Agradeço a MC Markinhos, Mano Teko, Guilherme Pimentel, Jackson Anastacio, MC Leonardo, Raphael Calazans e Repper Fiell por compartilharem a história deles comigo e pelas várias análises enriquecedoras.

2 Recomendo a leitura de "Culturas de periferia: entre o mercado, os dispositivos de gestão e o agir político" de Livia de Tomassi (2013) para uma análise de três cidades, São Paulo, Rio de Janeiro e Recife.
} 
conversas, trocas de experiências de ativistas que se encontram em eventos relacionados à causa. As redes sociais, em primeiro lugar o facebook, se revelaram meios de troca contínua e fonte de citações e expressões exemplares sobre a postura desses atores sociais e políticos e da sua luta. A autora se entende como mais um peer numa rede difusa com o norte "da luta por direitos", sem deixar de respeitar os limites do que uma pesquisa científica requer, ou seja, sem deixar de controlar o viés da proximidade. Pois, trata-se de uma pesquisa cientista política. Por questões de transparência fica declarado que a autora militou na campanha de MC Leonardo para vereador do Rio de Janeiro, vendo a luta do funk como questão primaria da luta "pelo direito à cidade", mesmo não passando de um aprendiz no que diz respeito ao funk. Considero necessário incluir no debate sobre ativismo sócio-político e publicação científica a questão do "cientista militante" cujo trabalho deve ser avaliado como qualquer trabalho científico.

O primeiro passo será um breve resumo sobre teorias de movimentos sociais. Em seguida é discutido o conceito de peer-to-peer (P2P) que norteia este trabalho. Serão apresentadas algumas características da teoria da produção do commons como é propagada pela P2P Foundation que dizem respeito às políticas participativas (particpatory politics). Estes aspectos contemplam uma participação horizontal diferente da mobilização civil como, por exemplo, em organizações não governamentais.

Em seguida serão aplicados estes aspectos ao caso da APA Funk do Rio de Janeiro em três passos: primeiro, recorrendo ao contexto histórico do funk carioca, da formação da APA Funk e dos eventos políticos desde então (3.1). Depois será analisada a estrutura da associação e a sua lógica de ação (3.2). Neste parágrafo será recorrido principalmente às falas dos próprios membros, dos textos oficiais (manifesto, cartilhas etc.), ferramentas de ação e as minhas próprias observações nos eventos da APA Funk.

\section{PARTICIPAÇÃO P2P: A REDESCOBERTA DA PARTICIPAÇÃO HORIZONTAL?}

Uma ideia principal deste artigo é averiguar até onde as teorias da produção entre pares em sua simplicidade conseguem abranger casos de participação política, principalmente a lógica de ação de alguns grupos sociais. Mas por se tratar de um estudo cientista social sobre movimentos sociais - APA Funk é uma associação de profissionais e amigos, mas claramente pode ser considerado um movimento social - faz-se necessário discutir brevemente as alternativas teóricas cientistas-sociais. 


\section{Teorias cientista-sociais de movimentos sociais}

Dentro das ciências sociais há várias correntes teóricas sobre movimentos sociais (Fox Piven/ Cloward 1977 sobre a institucionalização de movimentos populares, Gamson 1975 e McCarthy/Zald 1977 sobre mobilização de recursos, McAdam 1982 sobre a estrutura de oportunidades). Todas estas teorias clássicas, depois de tanto tempo, continuam influenciando as análises sobre movimentos populares. Mas têm limites que chamam por análises que consigam aumentar o escopo dessas teorias. A contribuição de Fox Piven e Cloward, por exemplo, sobre a questão da institucionalização ou não de movimentos sociais é um guia essencial para os desafios institucionais de movimentos:

But popular insurgency does not proceed by someone else's rules or hopes; it has its own logic and direction. It flows from historically specific circumstances: it is a reaction against those circumstances, and it is also limited by those circumstances. (CLOWARD; PIVEN, 1977, p.11)

Mas para o nosso caso chegam ao limite quando dizem:

It was an important insight, and once it had been achieved the conclusion followed not far behind that so long as lower-class groups abided by the norms governing the electoral representative system, they would have little influence. It therefore became clear, at least to some of us, that protest tactics which defied political norms were not simply the recourse of troublemakers and fools. For the poor, they were the only recourse. (CLOWARD; PIVEN, 1977, p. 3).

Pois no caso da APA Funk o protesto claramente faz parte, mas não foi o "único recurso que encontraram". ${ }^{3}$ Isso me leva a argumentar que vale a pena considerar teorias alternativas e provavelmente complementares - que procuram contemplar a variedade de estilos de participação política "inesperada" que encontramos hoje em dia. Pois as teorias de movimentos sociais, na grande maioria, se referem aos grandes movimentos que observamos no século $\mathrm{XX}$ : movimento feminista, estudantil, ecológico, direitos civis (civil-rights movement) etc. Estes movimentos representaram e ainda representam lutas muito amplas de exigências básicas dos movimentos e, portanto, tiveram uma força de mobilização imensa. Hoje as desigualdades talvez sejam tão profundas quanto antes, mas são distorcidas por discursos retóricos que tornaram a mobilização difícil. ${ }^{4}$ Este ponto é considerado no capítulo adicional da segunda

\footnotetext{
${ }^{3}$ Pode-se argumentar que se trata de um caso isolado e que faz-se necessário levantar mais dados. O nosso grupo de pesquisa $\mathrm{P} 2 \mathrm{P}$ iniciou um processo de mapeamento de projetos e dinâmicas peer-to-peer em Brasil, uma wiki, que pode ser encontrado aqui:

http://p2pfoundation.net/Category:Brazil_P2P_WikiSprint

${ }^{4}$ Os moradores de favelas claramente são privados de direitos cívicos básicos como por exemplo o direito a propriedade: a
} 
edição do clássico The strategy of social protest de outra corrente predominante nas teorias sobre movimentos sociais, a teoria da "mobilização de recursos" (GAMSON, 1975/1990):

Since 1945 the expansion the intelligence apparatus has added to the social control repertoire of authorities' sophisticated new ways of attacking challengers. (GAMSON, 1990, p.146).

O livro de Gamson é um compêndio completo que abrange as várias faces de estratégias populares e características de organização interna dos grupos e a segunda edição ainda conta com um novo capítulo sobre as carreiras dos integrantes de movimentos populares. Inclui análises sobre as condições externas dos movimentos, como as estratégias e ferramentas de controle social do estado e sem dúvida seria um guia interessante para fazer um macro estudo da APA Funk. Mas o que se vê nestas correntes como um todo, é a perspectiva de uma análise do ambiente e das estratégias como reação a este ambiente. No que veremos no caso específico da APA Funk, mas também em cada vez mais grupos, é o foco da preocupação com a forma interna. Mais e mais grupos ${ }^{5}$ definem as suas ações através da constituição interna, e a maneira pela qual agem consideram já como ferramenta da sua atividade social. Nesse argumento não se trata de estratégias, e sim como identidade coletiva e uma lógica de movimentos diferentes do tradicional.

As teorias sobre cidadania e sociedade civil já são mais predestinadas para trabalhar com entidades menores, na maioria, abrangem e conseguem explicar organizações não governamentais (ONGs), ou associações tradicionais como associações de moradores etc.

As ONGs por sua vez, pelo menos no que se pode observar no Brasil, hoje em dia, têm mais perfil de mini empresas do que braços de movimentos sociais e na sua estrutura são bem diferentes de associações. Geralmente concorrem em editais e grande parte das verbas dos editais é consumida pela burocracia da própria organização. Deixamos como provocação que o sistema de editais no Brasil fez com que boa parte das ONGs se tornasse intermediária, quase indispensáveis (como, por exemplo, o sistema judicial fez com os advogados).

polícia entra - armada - em casas e apartamentos de favela sem a necessidade de uma ordem judicial. Mas eles são cidadãoseleitores e as ações policiais são justificadas como ações necessárias para estabelecer a ordem democrática nestes bairros das cidades. Este discurso supostamente democrático distorceu a realidade e reduziu o escopo de argumentação crítica. Ouve-se e leia-se tanto nas redes sociais quanto em conversas alheias ou em conversas diretas, comentários do gênero "já temos x, y e z, o que mais querem?", atribuindo todas as melhorias (ainda poucas) à intervenção policial do estado. Grupos que criticam a forma da intervenção naturalmente enfrentam problemas de mobilização frente a esta satisfação com o mínimo.

${ }^{5}$ Recentemente participei no $2^{\circ}$ encontro de grupos de consumos responsável em São Paulo, Parelheiros $(23$ a 25 de agosto 2013) e dos 17 grupos presentes todos debatem constantemente a possibilidade de formalizar o grupo, mas optam contra por questões da integridade do grupo. Já em 2008 critiquei a certeza que Helmke e Levitsky (2006) tinham com respeito à formalização quando dizem que instituições/organizações ou outras entidades informais optariam pela formalização quando possam. (Stadler, 2008). 


\title{
A produção do commons e participação política
}

Nos seguintes parágrafos serão discutidos alguns componentes da teoria P2P que parecem muito indicados para a compreensão deste estudo de caso. Mas antes de qualquer coisa, é preciso comentar o fato de que para a ciência política a linguagem P2P pode parecer muito econômica. Fala-se de "bens", "recursos" e "produção" e de certo modo pode ser entendido como um manual para empreendimentos. O meu objetivo é justamente mostrar de como esta linguagem facilmente pode ser traduzida à participação política.

Commons $^{6}$ não é um termo muito estranho na ciência política, afinal uma câmara do parlamento inglês se chama House of Commons em contraponto ao House of Lords. A Câmara dos Comuns veio a existir na Inglaterra como uma exigência política das classes contribuintes (que pagaram impostos), classes inferiores às elites inglesas que dominaram a Câmara dos Lordes. O nome se refere à proveniência destes sujeitos, as comunidades (comunes), e os membros foram eleitos. O commons como conceito teórico, então é um pouco menos palpável por ser muito abrangente, mas fica nesta tradição das comunes, ou seja, das comunidades. A definição de Beatriz Martins, usada neste trabalho, resume em poucas palavras: "De forma resumida podemos dizer que os commons, são recursos de uso compartilhado." (2011: 369). ${ }^{7}$ Estes recursos podem ser bens materiais, tanto como ideias, conhecimentos ou outros bens imateriais. O conceito do commons, então, depende das diversas possíveis características adicionais que pressupomos. Uma dessas características considerada crucial é a não rivalidade dos bens imateriais:

\begin{abstract}
No caso de bens rivais, o acesso de uma pessoa a determinado recurso representa de alguma maneira a interdição ou perda do acesso a outros. Podemos pensar em qualquer bem dessa natureza, como uma caneta, um carro ou um CD. Se eu empresto a alguém, fico privado de seu uso. Já se transmito uma ideia, um software, um arquivo de texto ou de música, passo a compartilhar do uso desse bem com outra pessoa. Eu cedo, mas não perco, ao contrário, de alguma forma eu amplio. Amplio o uso desse bem e amplio também minhas trocas na economia da dádiva que modula as relações na rede. (MARTINS, 2011, p.370).
\end{abstract}

Um bem imaterial, porém essencial, são direitos. Alegando que a maioria dos direitos cívicos na sua versão mais ampla $^{8}$ são conquistas de lutas sociais, podemos aqui traduzir peer production também como produção de direitos sociais $\cong$ luta social, se feita com objetivos

\footnotetext{
${ }^{6}$ Sobre a questão de usar o termo inglês escreveu Beatriz Martins: "O termo em inglês, como alerta Silveira (2007), guarda uma riqueza semântica que pode ser perdida se simplesmente o traduzirmos para o português "comum". Por isso, a fim de preservar seu sentido mais amplo, de modo geral, os pesquisadores têm optado por manter a palavra no idioma original".

${ }^{7}$ Para uma categorização das características dos commons mais complexa veja Benkler (2007) e para uma discussão dele em português veja Martins (2011).

${ }^{8}$ Por exemplo, o sufrágio feminino, o casamento igualitário.
} 
políticos minimamente definidas. Aqui se faz necessário uma anotação importante sobre o uso do termo participação política que em inglês seria political participation e política participativa que seria participatory politics. Tradicionalmente participação política abrange a ação de cidadãos no sistema política, ou através da participação em eleições, em partidos políticos ou em movimentos sociais. Política participativa no geral se refere a sistemas com participação direta, como o orçamento participativo, em contraponto à democracia representativa. Como veremos no exemplo de Jenkins, nem todos os pesquisadores fazem uma diferenciação tão estrita.

Não é o escopo desta pesquisa, afirmar se a participação política hoje é muito diferente ou não. Ainda temos que estudar muito estes "novos" trends, sobre tudo nas revoltas que vêm acontecendo em várias cidades no Brasil em 2013. Mas claramente podemos afirmar que com as novas ferramentas de redes sociais, temos mais acesso os meios de produção, difusão e consumo de informação. Isto, por si só, já pode alterar a qualidade teórica de participação, mas não necessariamente a qualidade analítica. ${ }^{9}$ Uma aproximação a estes "atos de política participativa" pode ser:

The Youth and Participatory Politics study defines participatory politics as interactive, peer-based acts through which individuals and groups seek to exert both voice and influence on issues of public concern. Importantly, these acts are not guided by deference to elites or formal institutions. Examples of participatory political acts include starting a new political group online, writing and disseminating a blog post about a political issue, forwarding a funny political video to one's social network, or participating in a poetry slam. (COHEN et al, in Jenkins, 2012, grifo nosso)

Uma vez resolvido que podemos entender participação política como produção entre pares, no que segue apresento um pequeno catálogo de características de peer production compilado pela P2P Poundation que no próximo passo serve como guia da pesquisa de caso ${ }^{10}$ :

a. Anti-credencialismo: aqui se trata da natureza inclusiva da produção entre pares onde as capacidades de cada par pesam mais do que os credenciais formais. Isso claramente indica uma lógica onde o diploma não é necessariamente documento de entrada, o que não quer dizer que um diploma seja um ponto negativo, ele simplesmente não vale como comprovante principal da capacidade. Particularmente importante é que a falta de diploma não resulta na exclusão ex-ante.

b. Anti-rivalidade: contrário ao paradigma da escassez de bens, esta característica

\footnotetext{
${ }^{9}$ Quero dizer que mesmo com outros meios de participação, os processos não necessariamente mudam.

${ }_{10}$ Traduzo aqui de forma mais livre a lista que se encontra na wiki da p2p foundation: <http://p2pfoundation.net/ Category:Peerproduction>. Algumas características dos 14 citadas não são contempladas para simplificar um pouco o estudo e por considerar que elas- no que diz respeito à participação política - são muito parecidos a outras características (e.g. avaliação comunitária ex-post).
} 
promove o paradigma da abundância. Dispomos de uma abundância de recursos, mas não o enxergamos como abundância porque concorremos por estes recursos. Este ponto se refere ao que coloquei em cima, compartilhar um bem aumenta e não diminui o seu valor. Em adição aos exemplos de bens materiais já dados, podemos dar o exemplo de bens imateriais, como informação. Quanto mais pessoas dentro de uma sociedade tenham acesso a informação, mais pessoas podem tomar decisões cada vez mais equilibradas e conscientes.

c. Distribuição de tarefas: a participação não implica num emprego ou num papel e sim em tarefas específicas. A organização interna tradicionalmente funciona a base de distribuição de "papeis" complexos (por exemplo, presidentes, representantes etc) que muitas vezes implicam uma dimensão de honores. A produção entre pares se entende como um processo no qual se somem tarefas isoladas. Os colaboradores assumem estas tarefas conforme as capacidades para cada tarefa e não através de um suposto valor do currículo. Este ponto quebra com o paradigma da representação delegada, pois na prática todos os colaboradores são representantes.

d. Equipotencialidade: as pessoas são avaliadas pelas características que dizem respeito a tarefa que elas assumem. É comum encontrar em grupos (sociais) com uma lógica de participação mais tradicional a valorização "completa" de um colaborador (simpatia, quantidade e diversidade de capacidades etc.). Numa produção P2P cada um apenas necessita de uma capacidade adequada para uma determinada tarefa. A rigor não tem superioridade nas capacidades (a faxineira que faxina bem vale tanto quanto um engenheiro que calcula bem e de certa forma mais que um engenheiro que não calcule bem, pois este não cumpre a tarefa que lhe foi destinada). Essa característica aumenta de forma exponencial o pool de recursos para movimentos políticos, pois diminui a importância do currículo completo. Um exemplo um pouco caricata poderia ser que um colaborador de um movimento de trabalhadores não necessariamente precisa ter lido e estudado toda a literatura clássica de Marx e mesmo assim contribuir à causa. ${ }^{11}$

e. Benefício: a produção dos pares foca no benefício, e não no lucro. Este ponto quebra o paradigma capitalista do objetivo máximo da maximização do lucro e concentra no benefício. Fica claro que o lucro também entra na contra dos benefícios, mas é uma variável apenas. Por exemplo, a institucionalização de um grupo pode trazer consigo um lucro instantâneo (por poder receber doações ou concorrer em editais) o que pode desenvolver benefícios em longo

\footnotetext{
${ }^{11}$ Naturalmente isso inclui a total negação de características segundarias como sexo ou género, etnia ou cor de pele, orientação sexual etc. Se a tarefa é carregar peso não é necessariamente um homem que a assume, facilmente pode ser uma mulher com força suficiente para esta tarefa.
} 
prazo. Mas nem sempre este lucro é benéfico, pois pode implicar em “custos" alternativos como brigas internas e desgaste institucional.

f. Coordenação negociada: Conflitos são resolvidos num constante diálogo e não em decisões de cima para baixo. Aqui entra o conceito da organização horizontal, não regulada por grêmios. Quando tomamos o exemplo de sindicatos, vemos que têm uma estrutura bem representativa com grêmios eleitos que tomam decisões em nome dos associados/ sócios. Numa produção P2P idealmente partimos da instituição do consenso negociado.

g. Ausência de Permissão: Não é preciso ter uma permissão para contribuir ao commons, não se precisa ser "associado" ou convidado para contribuir à causa. Essa característica entende o processo produtivo como um processo amplo. Por exemplo, se o bem compartilhado é uma informação, cada um que produza e compartilhe a informação (seja num blog, numa rede social, ou num livro) contribui ao commons.

h. Prod-uso: Não existe uma separação estrita entre a produção e o consumo, diferente da lógica que produz para o consumo. O produtor também é consumidor e o consumidor também interfere de alguma maneira na produção. Este ponto é muito importante para a participação política, pois reconhece a cadeira inteira como o processo.

Estas oito características guiarão no próximo parágrafo a análise da lógica de ação e auto definição da APA Funk. Mas antes vale a pena resumir as seguintes observações.

Como foi visto já na tradução teórica, este conceito de produção também pode ser aplicado para os estudos de participação política. Pois, participação política de certa forma é uma produção de bens materiais ou imateriais, e estes bens podem ser altamente concorridos (verbas) ou não rivais (direitos civis). A lógica da produção de bens de uso compartilhado está marcada pelos eixos horizontalidade, inclusão/integração e diversidade.

Naturalmente, todos estes pontos são aproximações ideias o que seria uma peer production integral. $\mathrm{Na}$ realidade espera-se que ela se mostre em graus, pois os atores foram escolarizados no paradigma da organização vertical, dentro de hierarquias. O fechamento é com Cohen et al. que resumem esses desafios da seguinte forma:

The new horizontality refers to the new dynamics and players emerging through the social interaction, in fact to a wholly new institutional field. The new diagonality refers to both the new hybrid adaptations that occur when the vertical meets the horizontal, and the new mediating players that may arise after disruptive disintermediation has done its work. (Cohen et al, 2012, p.3, in Jenkins 2012 ${ }^{12}$ ).

$12<$ http://henryjenkins.org/2012/07/participatory_politics_new_med.html> 


\section{“QUEM É DE SOMAR, COLA": A APA FUNK (RIO DE JANEIRO)}

O lema da Associação de Profissionais e Amigos do Funk é "quem é de somar, cola". Ou seja, todos que quiserem contribuir de alguma forma, podem "chegar junto" e agir. Não se paga associação e os eventos são abertos e gratuitos. Não tem benefícios para aqueles que assumem cargos "oficiais" (presidência, tesoureiro) que se fazem necessário por se tratar de um ente reconhecido pela legislação brasileira. Neste parágrafo serão apresentados: primeiro o contexto social e político do funk e da formação da APA Funk e segundo alguns dados importantes sobre a APA Funk desde 2008 à 2013. Em seguida aplicarei o catálogo de características da peer production discutido anteriormente para mostrar que ele é um guia muito pertinente para este caso. Para finalizar, serão apresentadas um pouco mais em detalhe as formas de ação principais da APA Funk para comentar por último enquanto se trata de uma lógica de ação diferente.

\section{Contexto social e político do funk e da formação da APA Funk}

O funk carioca, desde os anos 80 vem vivendo uma realidade ambígua entre sucesso popular $^{13}$, discriminação política e perseguição policial. Por um lado o mercado do funk vem crescendo e ocupando cada vez mais camadas da sociedade carioca ${ }^{14}$, por outro lado os bailes ${ }^{15}$ nas comunidades/ favelas são discriminados e tocar funk numa comemoração privada numa casa particular numa comunidade com Polícia Pacificadora pode implicar no término da festa. ${ }^{16}$

$\mathrm{Na}$ segunda metade dos anos 90, justificado por eventos violentos, a presença de traficantes nos bailes e suposta apologia ao crime nas letras, os bailes chegam a ser interditados e o funk consequentemente criminalizado.

\footnotetext{
${ }^{13}$ Sobre o sucesso popular, veja Hermano Vianna (1990, p.244): Hoje, segundo pesquisa que realizamos em 1987, acontecem cerca de seiscentas festas funk (conhecidas como bailes funk) por fim de semana, atraindo um público de mais ou menos um milhão de pessoas. Esses números colocam o baile funk como uma das diversões mais "populares" da cidade. Só a praia parece atrair, com essa frequência, um público "fiel" maior.

${ }_{15}^{14}$ Há muitos que dizem que o funk é a música mais tocada no Rio de Janeiro.

15 "Os bailes funk atualmente podem ser reunidos em três categorias: "baile de corredor", baile normal" e "baile de comunidade". Entre o "baile normal" [exclui nota] e o de "corredor", a diferença reside na articulação entre o binômio espaço e tempo para o confronto. No primeiro, ele é controlado e limitado mais severamente pelos organizadores. No segundo, como assinalou um DJ, "a briga é organizada", isto é o baile é dividido em territórios, para que as galeras se confrontem abertamente. Nos dois tipos de bailes existem também as áreas consideradas neutras (acessos e bares, por exemplo). "Diferentemente das modalidades anteriores, no baile "de comunidade", como veremos, esses confrontos simplesmente não existem." (Cecchetto 2006, p.146)

${ }^{16}$ Temos os mais variados relatos de invasão policial em espaços privados relacionados ao funk, como proibição de festas de aniversário e casamentos.
} 
Hermano Vianna, um dos primeiros a pesquisar o funk brasileiro resumiu esse processo na primeira edição da revista RAIZ:

\begin{abstract}
A música, quando começou a ser produzida na cidade, era totalmente independente dos "comandos". Poderia ter continuado assim, se o poder público (com polícia também armada, algumas vezes dando tiros nos equipamentos) não tivesse fechado os bailes dos clubes, se os críticos musicais e as gravadoras não tivessem amaldiçoado o estilo (fortalecendo a pirataria), se o asfalto, por puro preconceito contra "som de pretos e pobres", não tivesse tentado destruir a cultura que os favelados estavam criando por eles mesmos. (HERMANO, 2005).
\end{abstract}

Uma interpretação parecida é encontrada da antropóloga Adriana Facina e o MC Leonardo, numa entrevista ao jornal Brasil de fato em 2009 quando comentam:

\begin{abstract}
Ao criminalizarem o funk, e o estilo de vida daqueles que se identificam como funkeiros, os que hoje defendem a sua proibição, são os herdeiros históricos daqueles que perseguiam os batuques nas senzalas, nos fazendo ver, de modo contraditório as potencialidades rebeldes do ritmo que vem das favelas. (FACINA, 2009)
\end{abstract}

Neste raciocínio, o funk vem sofrendo preconceito em primeiro lugar por ser "música de pobre, preto e favelado", aliás, uma visão da realidade que todos os profissionais e amigos do funk entrevistados compartilham e que se pode escutar ou ler (nas redes sociais) nas expressões de outros integrantes do movimento. ${ }^{17}$

Em 2007 o secretário de segurança do estado Rio de Janeiro, José Mariano Beltrame, aprova a resolução 013 que dá aos policiais o poder de vetar qualquer evento social, esportivo ou cultural no estado do Rio de Janeiro. Em favelas ocupadas pela Unidade de Polícia Pacificadora (UPP) os bailes e o funk sumiram completamente.

Em 2008 é aprovada a lei estadual 5.265, a chamada lei Álvaro Lins. Esta lei, através da criação de uma burocracia abundante impossibilita a realização de bailes "populares" em áreas sociais precárias. Ela cria um complexo catálogo de pré-requisitos para os bailes que faz com que de fato nenhum grupo popular consiga a permissão para o evento. Numa entrevista de fevereiro de 2012 para a Revista Forum, Guilherme Pimentel, amigo e co-fundador da APA Funk e assessor de direitos humanos na Assembleia Legislativa do Estado do Rio de Janeiro (ALERJ), comenta a lei da seguinte forma:

\footnotetext{
A lei regulamentava eventos de duas camadas sociais tão distintas. As raves tinham como cumprir os requisitos, mas os bailes funk, na prática, ficavam inviabilizados" e conclui que o "objetivo do projeto era jogar o funk na ilegalidade, sob a justificativa

${ }^{17}$ Outro que fala do funk e do preconceito é Pedro Alexandre Sanchez: A luta do funk contra o preconceito, Artigo para Revista Forum 08/02/2012.
} 
explícita de que estava ligado ao crime. A criminalização é um processo político, e o funk vem sendo historicamente criminalizado, sintoma de um sistema político que criminaliza os negros e pobres. (PIMENTEL, 2012)

\section{A APA Funk: uma outra lógica de participação política?}

Em resposta a essa perseguição da cultura funk, pessoas envolvidas com os bailes se juntam para questionar e combater de forma proativa esta política de repressão e em dezembro 2008 é fundada a Associação dos Profissionais e Amigos do Funk (APA Funk). Numa roda na casa da antropóloga Adriana Facina, tinham se encontrado ativistas de diferentes movimentos sociais e profissionais do funk e decidido de agir juntos contra a criminalização funk.

Logo no início da criação da APA Funk, surge a consciência da necessidade de uma lei que proteja o funk e o declare cultura. Foram MC Leonardo e Adriana Facina que escreveram a lei. O gabinete do deputado estadual, Marcelo Freixo, moldou o texto para respeitar as normas legislativas, mas depois devolveu a lei a MC Leonardo. Ele mesmo, como conta na entrevista, teve que colecionar as assinaturas dos deputados para a lei poder ser votada (com sucesso) na câmara.

No dia 25 de agosto acontece uma audiência pública na ALERJ e a APA Funk se faz presente com banners e muitos militantes presentes. Enfim, no dia 1 de setembro 2009, a Assembleia Legislativa do Estado Rio de Janeiro aprova a lei 'funk é cultura' (Lei 5543/2009) e no mesmo ato a lei 5544/2009 que elimina a lei Álvaro Lins. Mas enquanto a lei "funk é cultura" consegue com que abram espaços antes inalcançáveis como editais de cultura (2011) e até um programa diário na Radio Nacional Rio de Janeiro (2010), o maior arquivo da música popular brasileira, a proibição dos bailes nas comunidades continua. Em setembro 2013, de maneira inesperada, o governador Sérgio Cabral revoga a resolução 013 e em algumas comunidades os bailes voltam, por exemplo, no Complexo do Alemão. Mas integrantes da APA Funk como Mano Teko relatam de vários incidentes de proibições de bailes sem mais explicações por lado da Polícia Militar do Estado do Rio de Janeiro. Esta trajetória já mostra um perfil diferente de outros movimentos: o caminho pelo sistema representativo para combater leis e propor leis benéficas e a exigência de modificação de políticas públicas, como os editais. Enquanto muitos ONGs se tornaram especialistas na concorrência por editais, a APA Funk se manifestou a favor de uma alteração do sistema de editais.

Ao longo do tempo a APA Funk desenvolveu atividades constantes e repetitivas como as rodas de funk e o sarau da APA Funk. Guilherme Pimentel considera as rodas, criadas em 2008, o "principal instrumento político da APA Funk, (...) onde o foco é informação, 
mobilização e luta por direitos." As primeiras rodas foram uma inovação para "ocupar espaços" como explica o MC Mano Teko. Os bailes tinham sido proibidos, mas manifestações políticas não. Então organizaram rodas, mesmo com uma estrutura de som precária, e as declararam como momentos de manifestação política onde apenas se precisa informar as autoridades competentes (Guilherme Pimentel). Fizeram rodas na Central e em várias favelas do Rio de Janeiro e também em presídios da região metropolitano. Mas mesmo declarando o evento como manifestação política, o Repper Fiell recebeu ameaças de morte quando organizou a primeira roda do morro Santa Marta, este já sob o controle das Unidades de Polícia Pacificadora (UPP).

Em 2012 inicia-se o Sarau Apafunk, um evento mensal que acontece na rua no centro do Rio. Igual às rodas, o sarau está aberto e gratuito, com lista de inscrição para quem quiser se manifestar através do microfone. Geralmente estão convidados outros movimentos sociais para se juntar ao evento, como o Movimento Nacional da Luta pela Moradia (MNLM) e o Movimentos dos Trabalhadores sem Terra (MST). Também é comum que vêm parceiros convidados de outras cidades.

A isso se somam trabalhos e ações pontuais, como a elaboração (ou distribuição) de cartilhas e vídeos pedagógicos informativos. Estes documentos são gratuitos e acessíveis no homepage da associação. Um exemplo é a cartilha que rapidamente relata a história do funk carioca e explica para os profissionais do funk a situação dos direitos autorais e de editais. Outros exemplos para eventos pontuais são manifestações políticas como as grandes manifestações no Rio de Janeiro no inverno de 2013 e a participação solidária na greve dos professores no Rio de Janeiro em setembro de 2013.

Recentemente se fundou o "Bloco APA Funk". Através de financiamento coletivo, da catarse, a APA Funk conseguiu a verba para comprar os instrumentos e tem o previsto de desfilar pela primeira vez no Carnaval Carioca em 2014, com a intenção de ocupar mais um espaço social da sociedade.

No que segue retomarei o catálogo de características da peer production para aplica-lo ao caso da APA Funk. A análise se dará através dos documentos oficiais, como o manifesto e as cartilhas, que se encontram no site apafunk.org.br, das falas nas entrevistas e as declarações públicas nas redes sociais, e da própria observação nos eventos.

a. Anti-credencialismo: Pelo que pude observar, e pelo que se aprende pelos currículos dos entrevistados, não há nenhuma forma de exclusão a base da falta de credenciais. Os MCs, naturalmente, não possuem nenhum diploma. Mas ao falar de outros profissionais, como por exemplo, instrumentalistas, produtores ou equipe de som, sempre transpareceu uma avaliação ex-post das qualidades de cada integrante. O sarau mensal da APA Funk segue esta regra em 
teoria e em prática. Mano Teko disse em entrevista que "todos são iguais" que "tem lista de inscrição" e anuncia o sarau no seu site no facebook com a seguinte afirmação "Sem Tapete Vermelho, Sem Estrelismo. Aos que se posicionam através da poesia... SARAU APAFUNK!!!"”. Na prática pude observar a coerência com esta regra no sarau.

b. Anti-rivalidade: Todas as falas dos entrevistados e os documentos oficiais indicam o sistema de agregar valor através da multiplicação, seja isso de bens imateriais como informação e conhecimento ou de bens materiais como ferramentas, equipes de som etc. Exemplo primário são os bens imateriais. O funk é um estilo de música que cada vez mais envolve dinheiro. Há alguns poucos MCs e algumas produtoras que ganham muito dinheiro. Mas o MC comum ganha pouco ou até nada. Uma política da APA Funk é multiplicar informações aos profissionais do funk, para que saibam dos seus direitos (e.g. autorais) e para que sejam preparados. MC Markinhos comentou isso da seguinte forma: “O MC não sabe dos direitos dele. (...) O MC paga 10000 Reais num DVD (...). Quer ficar famoso (...) Nosso lado é: antes de assinar, tem que ter conhecimento para não se vender por dinheiro". E no manifesto encontramos: "Por isso, a APAFunk seguirá na luta pelo respeito aos direitos dos artistas do funk, bem como combatendo a discriminação e o preconceito" ${ }^{18}$. Numa lógica mercantil, os profissionais da APA Funk poderiam usar o próprio conhecimento para se destacar no mercado do funk. Não fazê-lo indica que seguem outra lógica. Como isso representa um ganho? A irradiação do funk, o combate do preconceito com esta categoria naturalmente abre novos espaços para os artistas. As conquistas legais e culturais fazem com que os artistas tenham cada vez mais fontes de sustento como os próprios bailes, editais, crowd funding. Neste caso a não rivalidade representa um ganho, pois através dela aumenta-se o alcance da subcultura. Em palavras simples, em vez de disputar poucos recursos, a solução é aumentar os recursos.

c. Distribuição de tarefas: Na entrevista, Guilherme Pimentel declarou que a APA Funk foi fundada por "uma demanda formal", depois de já percorrer um processo interno que “definiu as pilares políticas da APA Funk". Uma associação formalmente tem que ter uma presidência. A questão é se essa presidência implica num papel implica em certos honores ou se se trata de uma presidência pro forma. No caso da APA Funk, pelo que se pôde observar, a presidência é pro forma. Mano Teko, atual presidente da associação declarou em entrevista que assumiu a presidência para "trabalhar junto", mas não para mandar em ninguém, e que "não muda nada". Jackson Anastácio, sócio amigo e integrante deste os primórdios da associação compara a distribuição com o movimento estudantil: "O movimento estudantil é tão elitizado

\footnotetext{
${ }^{18}$ A APA Funk. Disponível em: <http://www.apafunk.org/ a_apafunk.html〉. Acesso em: 12 ago. 2014.
} 
que você não precisa estar na base para fazer. Você vira um dirigente (...), já fui pra congresso da UNE sem nunca ter sido universitário. (...) Hoje vejo o quanto é distorcido esta realidade. (...) Hoje vejo isso com críticas severas.” Aqui então temos uma clara diferenciação do sistema de honores e carreiras dentro do movimento que encontramos em muitas outras falas. Segundo Guilherme Pimentel e Jackson Anastácio, a decisão da não profissionalização e consequentemente não remuneração da diretoria foi uma decisão consciente do coletivo. Houve vozes a favor da profissionalização e de um pagamento de "ajuda de custo", mas isso foi descartado.

d. Equipotencialidade: O próprio lema “quem é de somar, cola” já é uma introdução ao pensamento equipotencial. O movimento entende que a vontade de contribuir é um começo, mas também implica a necessidade de cumprir o compromisso assumido: É muito comum o Mano Teko publicar comentários como "colou, porque soube somar". Ou seja, temos a avaliação ex-post do prometido e do cumprido e o ponto essencial para avaliação é contribuir de alguma forma.

e. Benefício: Numa entrevista recente, Mano Teko constatou que o objetivo da APA Funk está na "discussão das pautas" e não na melhoria da situação de apenas um pequeno núcleo. Os objetivos são a multiplicação do conhecimento e da irradiação do movimento. A associação não cobra dos participantes e tampouco os paga. Na mesma entrevista deixa claro que participar na APA Funk não se ganha de imediato em termos financeiro, ou seja, não se ganha contratos ou algo do gênero (isso pode ser entendido como um complemento à característica da distribuição de tarefas e não empregos). A ideia é beneficiar a causa: "não temos que mostrar as pessoas que foram importantes, mais o quanto o funk foi importante para as pessoas" (MC Leonardo).

f. Coordenação negociada: O funcionamento interno, como foi possível observar e como foi transmitido nas entrevistas, qualifica como organização horizontal com consenso como regra de decisão e o muitas vezes mencionado "papo reto". Jackson Anastácio relatou a sua impressão da primeira reunião depois da vitória da lei "funk é cultura” na ALERJ: “(...) foi um caos. Uma "porradaria" (...) que eu não estava acostumado. Porque o ambiente é bem diferente da esquerda tradicional, aonde a gente faz críticas, mas as críticas são veladas, seu filho da puta, você não diz essas coisas, você tem até vontade, mas você não diz. Lá não, diz. (...) Disse, é a única coisa que acaba depois da vitória. (...) Eles não, eles tocam aquilo e saem da reunião a tomar uma cerveja como nada tivesse acontecido. (...)" Continua dizendo que primeiro tinha percebido isso como "embrutecimento", mas que depois aprendeu que o "papo reto" deles significa $100 \%$ sinceridade e que a questão é resolver o assunto seja de qual forma 
for. Esta forma varia de grupo à grupo através dos códigos que os integrantes compartilham. Problemas, questionamentos e outros assuntos de divergência idealmente são debatidos nas reuniões oficiais.

g. Ausência de Permissão: Com os eventos que apresentei em cima, a roda e o sarau, a APA Funk opta por ações que mostram uma linha de ação inclusiva e sem censura. Considerando "todas as formas de protesto legítimas" (Mano Teko no Saurau Apafunk de agosto 2013 e MC Leonardo em entrevista). Os eventos são abertos, onde se passa informações e deixa o micro no alcance para todos. Os eventos acontecem em espaços públicos ou abertos e não se paga entrada. Raphael Calazans do Morro do Alemão, integrante da APA Funk e do movimento Nós por nós resume assim: "O funk é democrático, a favela é democrática. O microfone está pra todo o mundo".

h. Prod-uso: A APA Funk é uma associação de profissionais e amigos do funk e tem duas categorias de sócios: sócio profissional e sócio amigo. Podemos entender que é um grupo de produtores e consumidores. Guilherme Pimentel é sócio amigo e relata que ao elaborar o estatuo sugeriu que tivesse as duas categorias com a seguinte diferença: sócio profissional pode votar e se eleger, sócio amigo "não tem voto, mas tem voz". Continua relatando que os profissionais estranharam esta regra pois consideraram as contribuições dos amigos tão importante quanto dos profissionais. Mas insistiu para proteger a associação como um grupo que defende em primeiro lugar o funk e os seus raízes e não o funk de consumidores. Considera que pela voz, o amigo/consumidor já está incluído no processo.

Vimos que há muitos indícios de que a lógica e prática do funcionamento da APA Funk seguem o catálogo de características da produção entre pares como proposta pela P2P Foundation. Pudemos ver que os eixos horizontalidade, inclusão/integração e diversidade traduzem bem esta lógica e prática.

A identidade deste movimento pode ser mapeada de diversas formas: Todos declaram o "favelado como protagonista", mas o movimento é inegavelmente diverso. O subúrbio e a favela são locais físicos, mas o sarau acontece no Centro do Rio de Janeiro. ${ }^{19}$ A legislação é um espaço político e o carnaval e a parada funk são espaços sociais a serem conquistados.

O histórico da APA Funk claramente aponta um conceito diferente de luta política dentro do contexto sociocultural da organização e dentro do contexto interno do funk. Em vez de optar pelo caminho único do protesto, opta por um caminho que também percorre o sistema político representativo. Como foi relatado de muitos integrantes com os quais falei, grande

${ }^{19}$ E este lugar também não é escolhido à toa. Acontece nas portas da ocupação Manoel Congo do MNLM, parceiro direto da APA Funk. 
parte dos "funkeiros" que estava presente na comemoração na ALERJ e na passeata que foi até a LAPA em setembro de 2009, não tinha engrossado ou apoiado o movimento antes. Apareceu naquele dia. Mas neste momento também pesou a lógica da não importância de cabeças e sim de conquistas, ou seja, da integração da diversidade.

\section{CONCLUSÃO}

Neste artigo juntamos uma teoria ainda pouco representada nas conferências tradicionais das Ciências Socais, um conceito de Peer to Peer Governance, com um caso empírico menos representado ainda: o funk brasileiro (funk carioca). A Ciencia Política mais tradicional ainda não reconheceu o potencial do funk para estudar as manifestações políticas nas cidades brasileiras, especificamente da periferia das cidades. Neste estudo de caso discutimos a transformação de atores socialmente, profissionalmente e politicamente marginalizados em atores políticos que se fazem presentes no sistema representativo e nos espaços políticos e sociais. Ao final, são cidadãos e como tais têm direitos e a legislação tem o dever de considerar e garantir estes direitos.

Analisamos a sua lógica de ação e participação política e examinamos a sua geografia social, mapeando as suas atividades pelo prisma da identidade coletiva. Demos um panorama maior das dificuldades de ser um ator dentro do sistema representativo que não só representa os historicamente despolitizados, mas também uma lógica de participação claramente diferente do mainstream. A APA Funk em vários momento mostra que está muito preocupado com a forma de ser e de agir e considera isso parte da sua luta social. Vimos que segue os eixos de horizontalidade, inclusão/integração e diversidade.

Vimos um mapa da identidade coletiva diverso com várias dimensões, mas ao mesmo tempo muito bem definido e claro. Recorro a Guilherme Pimentel quando diz:

\footnotetext{
Graças a Roda de Funk a Apafunk conseguiu todas essas conquistas. A Roda de Funk passou por favelas, universidades, movimentos, sindicatos, congressos, cadeias, praças públicas, instituições... Então, essa política "tradicional" que a Apafunk opta inclui os meios de movimentos sociais, ou seja, não se restringe a uma atuação na institucionalidade. A base de tudo é a rua e as pessoas, sem isso não temos nada. (PIMENTEL, 2009)
}

Raphael Calazans resume muito bem esse espaço entre redescoberta e reinvenção quando diz que o "baile é um direito cultural que a favela deu a ela mesmo. Tomaram de nós, nós o inventamos de novo". Trata-se neste trabalho de um trabalho introdutório. Ou seja, não deixou espaço para analisar em detalhe a constituição desse movimento e os muitos desafios 
que enfrenta. Ficou muito claro nas entrevistas que como em qualquer movimento de direitos civis e políticos, os desafios externos e internos são imensos. A diversidade de interesses, códigos, temperamentos etc., encontramos num grupo de pares como em qualquer outro grupo. O consenso por si só já é um desafio constante que exige energias, paciência e disposição.

Mas consegui mostrar que as teorias sobre a produção entre pares é uma ferramenta interessante para incluir casos de movimentos sociais que em muito seguem as linhas tradicionais, mas de perto revelam dinâmicas muito diferentes. Estudar e entender melhor estas dinâmicas aumentará em muito o alcance das Ciências Sociais.

\section{REFERÊNCIAS}

BENKLER, Yochai. A economia política dos commons. In: SILVEIRA, Sergio Amadeu da (Org.). Comunicação digital e a construção dos commons: redes virais, espectro aberto e as novas possibilidades de regulação. São Paulo: Fundação Perseu Abramo, 2007. p. 11-20.

CECCHETTO, Fatima. Galeras funk cariocas: os bailes e a constituição do ethos guerreiro. In: ZALUAR, Alba Maria; ALVITO, Marcos (Org.). Um século de favela. Rio de Janeiro: FGV, 2006. p. 145-165.

COHEN, Cathy et al. Participatory politics: new media and youth political action. Youth \& Participatory Politics Survey Project, Oakland, p.2-42, 01 dez. 2012. Disponível em: <http://ypp.dmlcentral.net/sites/default/files/publications/Participatory_Politics_New_Media_a nd_Youth_Political_Action.2012.pdf>. Acesso em: 13 ago. 2014.

FACINA, Adriana; MOTTA, Leonardo Perreira. O funk no contexto da criminalização da pobreza. O Brasil de Fato. São Paulo, p. 7-7. 01 jan. 2009. Disponível em:

<http://www.apafunk.org/imagens/imprensa/brasil_de_fato-2009jan.jpg>. Acesso em: 12 ago. 2014.

GAMSON, William. Strategy of social protest. 2. ed. Belmont: Wadsworth Publishing Company, 1990.

GAMSON, William. Strategy of social protest. Belmont: Wadsworth Publishing Company, 1975.

HELMKE, Gretchen; LEVITSKY, Steven. Informal institutions \& democracy: lessons from Latin America. Baltimore: The John Hopkins University Press, 2006.

JENKINS, Henry. Participatory politics: New Media and Youth Political Action. 2012. Disponível em: <http://henryjenkins.org/2012/07/participatory_politics_new_med.html>. Acesso em: 13 ago. 2014

MARTINS, Beatriz Cintra. Autoria, propriedade e compartilhamento de bens imateriais no capitalismo cognitivo. Liinc em Revista, Brasília, v. 7, p.358-374, jan. 2011. Semestral. Disponível em: <http://revista.ibict.br/liinc/index.php/liinc/article/viewFile/423/319>. Acesso 
em: 13 ago. 2014.

MCADAM, Doug. Political Process and the Development of Black Insurgency: 1930-1970. Chicago: University of Chicago Press, 1982.

MCCARTHY, John D.; ZALD, Mayer N.. Resource mobilization and social movements: a partial theory. American Journal of Sociology, Chicago, v. 82, p.1212-1241, 1977. Disponível em:

<http://www.jstor.org/discover/10.2307/2777934?uid=3737664\&uid=2\&uid=4\&sid=21104056 509281>. Acesso em: 14 ago. 2014.

PIVEN, Frances Fox; CLOWARD, Richard A. Poor people's movements: why they succeed, how they fail. New York: Vintage Books, 1977.

SACHEZ, Pedro Alexandre. A luta do funk contra o preconceito. 2012. Disponível em: <http://www.revistaforum.com.br/blog/2012/02/a_luta_do_funk_contra_o_preconceito/>. Acesso em: 14 ago. 2014.

STADLER, Julia. Informelle Institutionen jenseits normativer Forschung: rückschlüsse aus dem institutionellen Design des brasilianischen Wahlprozesses.Lateinamerika Analysen, Hamburgo, p.3-22, fev. 2008.

TOMASSI, Livia de. Culturas de periferia: entre o mercado, os dispositivos de gestão e o agir política. Política \& Sociedade, Florianópolis, v. 12, n. 23, p.11-34, 2013. Quadrimestral. Disponível em: <https://periodicos.ufsc.br/index.php/politica/article/view/21757984.2013v12n23p11>. Acesso em: 14 ago. 2014.

VIANNA, Hermano. Funk e cultura popular carioca. Estudos Históricos, Rio de Janeiro, v. 3, n. 6, p.244-253, 1990. Semestral. Disponível em: <http://bibliotecadigital.fgv.br/ojs/index.php/reh/article/view/2304/1443>. Acesso em: 14 ago. 2014.

VIANNA, Hermano. Entregamos o ouro ao bandido. 2005. Disponível em: $<$ http://revistaraiz.uol.com.br/portal/index.php?option=com_content\&task=view\&id=42\&Itemi d=57>. Acesso em: 15 ago. 2014. 